Tomislav Brlek

University of Zagreb

\title{
The Present Moment of the Past: History in and out of Literature
}

\begin{abstract}
Starting from Timothy Bahti's claim that "literary studies in the university are still the heir to the historicism after Hegel," readily verified by sundry historically organised takes on literary criticism and theory steadily advancing towards the present moment of comprehension, even as the true sources of the thought of the authors under scrutiny as well as of the actual origins of critical problems are unfailingly revealed to stem from the "real world," the paper aims to present T.S. Eliot's very different thinking about literature, criticism and history as a salubrious contravention of the worldwide dominance of approaches to reading works of literature predicated on unexamined notions of context and identity, which Timothy Clark dubbed "institutional Americanism," contending that it is no accident that the final thesis advanced by the historian Elco Runia in his recent Moved by the Past, which proposes a complete overhaul of certain certainties on which how we conceive of the past is predicated, should have a distinctly Eliotic ring to it: "By burying the dead we create not our future, but our past."
\end{abstract}

Key words: history, literature, modernity, hermeneutics, theory, T.S. Eliot, "institutional Americanism"

The distinction between past and present unavoidably underpins the very attempt at conceiving to conceive history, and in fact Jacques Le Goff posits that this is an insight most to the purpose in the writing of history. At least since Saint Augustine, the notion of the past has been inconceivable but in relation to the tripartite structure of past/present/future, the beginning of the present or contemporary moment being especially complex and including a most intricate compound of presuppositions on the collective level. For 
this reason, Hegel's fabled "burden of history" weighing down the enterprise of historiography is not the same for every nation or culture, and Le Goff singles out the United States as a specifically daunting instance of overdetermination of relatively recent events due to the lack of a long autochthonous history (cf. 2). In proposing that this rather particular relation to the past haunts the purview of American criticism no less than its history, this piece takes its cue from T.S. Eliot's comparison of Hawthorne and Henry James: "Both men had that sense of the past which is peculiarly American, but in Hawthorne this sense exercised itself in a grip on the past itself; in James it is a sense of the sense" (1918; in 2014a: 738).

It is the break with the past that enables us to perceive and therefore potentially to study it, but by the same token, it makes the past irretrievably alien to us, placing it forever out of our reach. The ruptures and discontinuities, resurgences and gaps, revisions and inconsistencies all bear witness to the fact that the dialectic in which the past and the present are entangled cannot be eschewed. One must of necessity be separated from the other, but never can be completely. Marc Bloch states the problem thus: "Incomprehension of the present is the inevitable result of ignorance of the past. But it is perhaps just as fruitless to struggle to understand the past if one knows nothing about the present" (qtd. in Le Goff 18). In other words, there can never be any understanding of the past as such except from a particular historical standpoint. Ceaselessly interpreting each other, the past and the present are entangled in a particular kind of hermeneutic feedback.

In actual fact, there is no past as such; it only comes into being when put into the perspective of a specific approach to it. Historical events are a rather paradoxically named category, since they can only come into being by virtue of a twofold process: they are rendered historical-i.e. amenable to comprehension - at the price that they stop taking place-i.e. being events. What is required is, on the one hand, selection from the all-encompassing backdrop and, on the other, embedding into a (more often than not, narrative) heuristic framework. And both selection and embedding are based on a whole set of presuppositions, motives, and aims ruled by some underlying 
epistemology or other: "The past is constantly being constructed and reinterpreted, and it has a future that is an integral and significant part of history" (Le Goff 108). Precisely because the whole of the past must forever be ungraspable in its multifariousness, history is always a narrative structure of some sort. In short, literature will inexorably underwrite the historian's brief. In a radical challenge to historiography's business-as-usual attitude, Elco Runia has recently proposed a complete overhaul of certain certainties on which how we conceive of the past is predicated:

\section{FOURTH THESIS:}

People start to make history not despite the fact that it is at odds with-yes, destroys - the stories they live by, but because it destroys the stories they live by.

I would like to remark in this connection that we routinely assume that our history is behind us. In the sense, however, that after a sublime historical event our worldview lags behind with what was all too possible, our history really is before us. We have to "catch up with it"-as the nineteenth century tried to catch up with the French Revolution, and as we, at the moment, are still trying to catch up with what the dual World War of the first half of the twentieth century has shown to be possible. I do not think-as Humboldt did-that we remain forever foreigners in the palaces we erect. Rather, we try to make them habitable. If the event we have brought about is too conspicuous to be smuggled away, catching up with it may even be a psychological necessity. (8)

Contrary to the usual practice of historiography, in order to comprehend what took place, the very taking place of an occurrence needs to be retrieved, i.e., conceived as something that has not been anticipated precisely because it could not have been foreseen.

Historians try, as Ranke said, "um die letzte und nächste vergangenheit mit der früheren in Einklang zu bringen" ("to bring recent history [i.e., the French revolution] into harmony with what happened before"). Making a palace habitable, "taming a monster," has, however, a rather annoying conse- 
quence: it obliterates its most salient feature, namely, the fact that it was an underdetermined answer to the question "Why not?" This can perhaps be seen most clearly in the American Declaration of Independence. The famous phrase "we hold these truths to be self-evident" suggests that these "truths," though perhaps unrecognized and unfulfilled, had always been there-and that the revolutionaries only gave them their due. But that, of course, is a typical ex post facto account. The decision to throw off the British yoke was not the result of "self-evidence." On the contrary: only after the irreversible step had been taken did it occur to Thomas Jefferson that the reasons for doing so were not contingencies but "truths," and not just truths but "self-evident truths." The "self-evident truths" didn't create the event, the event created "self-evident truths." Sublime "acts of people" like the American rebellion transform consciousness to such an extent that the status quo ante becomes unimaginable the moment the status quo post becomes self-evident. Differently put: the one thing without which the sublime historical event could not have taken place-our acting upon our impulse to make a difference-evaporates in the process of coming to terms with it. This, in fact, is my fifth thesis: FIFTH THESIS: The more we commemorate what we did, the more we transform ourselves into people who did not do it. (8-9)

Protestations to the contrary notwithstanding, these assumptions are emphatically not assumed in literary and cultural criticism as these are practiced today. Rather, the fundamental postulates of literary and cultural history are what they have always been since these disciplines came into view in the nineteenth century: that events come about due to their historical context, that change takes place developmentally, and that this change is the unfolding of a notion, principle, or some other ideal entity. Even though it may no longer be the unexamined presupposition it once was (although this is in fact highly debatable), a hypostasised reality actually taking place "out there" still refuses to give way to the view that all contextual evidence-precisely by virtue of being evidence and inasmuch as it needs to be deciphered and interpreted, that is, "read"-is textual in nature. While there is no doubt that the relationship between text and context is, as Hayden White put it, crucial for "historians of anything whatsoever" (186), for historiography to assume 
the existence and nature of the very object of its inquiry (i.e., of the historical past) would amount to an instance of petitio principii.

The historically real, the past real, is that to which I can be referred only by way of an artefact that is textual in nature. The indexical, iconic, and symbolic notions of language, and therefore of texts, obscure the nature of this indirect referentiality and hold out the possibility of (feign) direct referentiality, create the illusion that there is a past out there that is directly reflected in the texts. But even if we grant this, what we see is the reflection, not the thing reflected. (209)

As if moving a flashlight in the dark, to adopt a somewhat imprecise comparison, the context is illuminated, and in a sense created, solely by the hermeneutical moves of the text at hand, which can shed light on and bring into focus only certain parts of the context, the supposed totality of which is bound to always remain out of reach.

While this might lead one to expect countenance of the modern in literary matters - as White for one has suggested might be favourable-even the most cursory of glances at the critical practices prevalent in the United States - and by extension of its academic reach, everywhere else-patently demonstrates that the inverse actually happens to be the case. The urge to look for history "as it really happened," instead of wasting one's time on textual nuances, and to do so on the basis of evidence supposedly "out there," as opposed to the speculative abstractions of what is dismissed as "theory," reigns unchallenged in the humanities - as witness not only the number of works devoted to the "histories" of this, that, and the other, but more importantly the self-styled "historical" viewpoint of virtually all current critical approaches. The danger this tack is fraught with has been succinctly pointed out by Antoine Compagnon: "The paradox is obvious: you are using context to explain an object that interests you precisely because it escapes this context and survives it" (10). Runia goes even further:

Yet, precisely because our mindset resists it, fathoming how the exhilarating, 
frightening, sinful, sublimely new comes about should be a question right up the alley of theorists of history. In recent decades however, theorists of history stuck to being in their right minds rather than venturing into the disposition from which the new emerges and from which this emergence can be understood. It is, on consideration, quite beyond the pale: in a century abounding in discontinuities, theorists of history have almost exclusively focused on what historians do instead of on what happened in history. (178)

Timothy Clark even coined the phrase "institutional Americanism" (24) to describe the worldwide dominance of approaches to reading works of literature predicated on unexamined notions of context and identity. Its defining trait is the tendency to conceive of instruction as a progressive mastering of a set of tools for manufacturing "critical" readings. The discursive approach these readings employ might be described as inquisitorial, for it is a pronounced feature of this discourse that it relies upon an all-explanatory interpretative schema that is rather crudely causal, holding everything in the text "to be determined by its conditions of making" (159). It is also extremely "self-righteous" (21) and tends to view any uncertainty, ambivalence, and ambiguity, to say nothing of irony, as evasion. In practice, this tends to produce sweeping panoramas of literature (and much more beyond) that are very often the result of "inaccurate library cramming" (26). This is hardly surprising, as it is certainly not disturbed by anything so trivial as reading, its main concern being nothing less than identity.

The text is only an illustration, a puzzle to be solved, for "the fundamental claim of this critical practice is that a notion of identity, either as given or striven for, can serve as an exhaustive principle of explanation for anything in or of the text at issue" (17). The text as such and in itself is of no significance, but a means to the higher end of moral instruction. Being mere extensions of their author's identities, all texts are exempla: "Texts and people are continually subjected to kinds of trial procedure designed to either condemn or acquit them of degrees of complicity in metaphysical/colonial/patriarchal thinking" (20). Such readings, "insidiously reductive" as they are "in that they 
pivot around one unexpressed but all-determining norm, that of a supposedly natural drive towards self-definition" (22), come across as a motley of nifty catchphrases, lofty clichés, and righteous sloganeering.

Almost a century ago, T.S. Eliot had already noticed a similar tendency when he wrote about a certain critical pronouncement that it represents "the Symbolist Movement after it has been boiled down in an American University" (1917; in 2014a: 597). The French reference is particularly a propos in the present context, for, as Susan Sontag pointed out half a century later, not incidentally introducing the work of Roland Barthes, the modern tendencies that have long occupied "the central position in contemporary letters" in France tend to be "regarded as marginal and suspect by the Anglo-American literary community," no more than a provocative minority current, labelled "avant-garde" or "experimental" literature (xiii). Although this goes a long way in explaining why, for instance, Jonathan Littell recently chose to write in French what is in many respects, as Walter Benn Michaels argued (cf. 2013), an exemplary instance of the Great American Novel - Les Bienveillantes (2006) or The Kindly Ones - the more pressing query should perhaps be how it is that in America the past is, in Faulkner's memorable apothegm, "never dead. It is not even past" (535). That a propitious way out of this peculiar conundrum elaborated in the poetical and critical writings of T.S. Eliot, from whom the title of this paper is appropriated, has on the whole gone unnoticed despite the ample currency of his work, might in and of itself suggest that what is really at stake in discussions of the relations that obtain between literature and history is the notion of the modern.

To anticipate somewhat but also recapitulate, here is Runia's concluding thesis, interestingly presented under the rather Eliotic chapter heading "Burial of the Dead":

by committing sublime historical deeds, by doing things that are at odds with our identity, we place history outside ourselves. Committing history thus is a kind of burial: we take leave of ourselves as we have come to know ourselves and become what we as yet do not know. In the process we come to see 
what is lost forever: what we are no longer. This is my tenth and final thesis: TENTH THESIS: By burying the dead we create not our future, but our past. (16)

In spite of his general reticence in this regard, Eliot does avail himself of the term modern on various occasions in his miscellaneous writings and sometimes even in their titles, as witness After Strange Gods: A Primer of Modern Heresy (1933) and Essays Ancient and Modern (1936). The most explicit use of the word is perhaps to be found in The Use of Poetry and the Use of Criticism: Studies in the Relation of Criticism to Poetry in England. Based on his lectures delivered at Harvard in 1932-1933, when he was Charles Eliot Norton Professor of Poetry, the book presents Eliot at his most academic. The penultimate chapter, "The Modern Mind," opens with the discussion of the "progress in self-consciousness," supposed to be characteristic of the subject the chapter-title refers to. Eliot is quick to point out, however, that he has been charting this "progress" throughout the preceding discussion of conceptions of poetry and that it is not to be taken as being necessarily accompanied by "an association of high value," since it cannot be "wholly abstracted from the general changes in the human mind in history." And that "these changes have any teleological significance is not one of [his] assumptions" (2015b: 668). But he did write that the task of the critic is "to determine what is meant by 'modern' poetry, and to trace, among the variety of currents and eddies, what is the line of true poetry, as distinguished from mere novelties" (1920; in 2014b: 212).

Eliot was not modern in the sense that he belonged to the period textbooks call "modernism" to a large extent because he was averse to any form of historicist narratives, as The Use of Poetry and the Use of Criticism makes abundantly clear. Ostensibly charting the history of poetic criticism in England, Eliot in fact undermines the possibility of any such history. There is continuity, but, and this is all important for Eliot, there is also the perspective from which the continuity is perceived: 
Amongst all these demands from poetry and responses to it there is always some permanent element in common, just as there are standards of good and bad writing independent of what any one of us happens to like and dislike; but every effort to formulate the common element is limited by the limitations of particular men in particular places and at particular times; and these limitations become manifest in the perspective of history.

No "objective" history is possible - precisely because there is no escape from history. It is perhaps a commonplace that "our criticism, from age to age, will reflect the things that the age demands," but it is equally important to notice that, as "each age demands different things from poetry," these demands "are modified, from time to time, by what some new poet has given." And we are not exempt from this predicament: "Our contemporary critics, like their predecessors, are making particular responses to particular situations." Which is not to deny the need for histories, only to realise their relativism, since "the criticism of no one man and of no one age can be expected to embrace the whole nature of poetry or exhaust all of its uses" (2015b: 680). All the periods are presented as relative to one another and at the same time each as absolute on its own terms.

At the outset, Eliot writes, "my subject is not merely the relation of criticism to poetry, if by that we assume that we already know what poetry is, and does, and is for. Indeed, a good part of criticism has consisted simply in the pursuit of answers to these questions" (580). Unlike the historicist, but like the critic, he does not know what he is looking for. The danger he thus tries to avoid is the one that plagues much contemporary writing in the humanities: generalisation from a privileged example. The usual reason for "the unsatisfactoriness of our theories and general statements about poetry is that while professing to apply to all poetry, they are really theories about, or generalizations from, a limited range of poetry." For we are "apt either to shape a theory to cover the poetry that we find the most moving, or-what is less excusable-to choose the poetry which illustrates the theory we want to hold" (679-80). Rather, one must "start with the supposition that we do 
not know what poetry is, or what it does or ought to do, or of what use it is." In fact, we "may even discover that we have no idea what use is; at any rate we had better not assume that we know" (580).

In counter distinction to the dominant practices of both literary history and theory, Eliot - like Derrida or Bakhtin, for example - rejects a simplistic linear understanding of history, in which periods (or poetical and critical schools) neatly follow and develop, eventually discrediting in order to replace one another, all the while remaining curiously on a prescribed course. Over against this essentialist "merry-go-round" view, in which new interpretations of a given period amount to nothing more than a changing of the guards on painted horses, Eliot argues for a complex interrelation of the past, the present, and the future as all mutually informing and constituting each other. One important consequence of accepting this view is that a particular critical position under discussion should be seen more as situated-and therefore to be judged as, for example, aligned, incongruent, or conflicting with other positions available at a given point in time-rather than as primarily oriented against all or some of those that preceded it. This problematic is in its turnand most pertinently in the context at hand-inseparable from the concept of identity.

It is nothing short of curious to see the view that Eliot may once have had a point, but that, as they say, times have changed espoused by the radical proponents of the historicist outlook. It was Fredric Jameson who put forth a striking assertion that those works that are "part of the so-called canon and are taught in schools and universities" are thereby deprived of any thought-provoking potential, for this very fact, he claims, "at once empties them of any of their older subversive power" (1998: 17-18). It is not clear what subversive power Jameson and his ilk could ever have conceivably claimed for their own theories, which had long since become part of "the so-called canon" of theory and are surely taught in the universities. It is, however, in regard of such considerations that the question Jameson once asked should be considered: "But is T.S. Eliot recuperable?" (1991: 303). From where Jameson stands, the viability of this operation is to be gauged by the profit it would yield for a 
given academic project. And it is a widely accepted contention that the relegating of modernism to a closed historical period is one such project.

As exemplified by Eliot, the modernist stance, by means of drawing attention to its own strategies of representation, foregrounds precisely what historicism sometimes preaches but always steers clear of in practice- to wit, the historical context. In this it contrasts strikingly with any return to history in an ahistorical manner, which proceeds by ignoring the historical nature of historical enquiry. The various movements, schools, "studies," and "-isms" in vogue in the humanities for the last couple of decades have thus more often than not tended to practice just such ahistorical historicism by no means inadvertently, but for a very good reason. A case in point is provided by, among others, Frank Lentricchia, when, in a widely accepted practice, he rewrites "Tradition and the Individual Talent" point for point as an argument against Eliot (cf. 118ff). To lack a "historical consciousness," Lentricchia writes, giving credit to Kenneth Burke, "to be without a sense of history is not only to be without a sense where we are but also to be disqualified as agents of change." Historical consciousness is nothing less than a precondition for revolution: "To be without a proper sense of history is necessarily to be complicit with all that is, with the institutions and the authorities in dominance" (119).

This failing is what Eliot purportedly shares with so-called theory and, in an interesting case of begging the issue, Lentricchia proceeds to claim that what, for instance, Paul de Man "provided" was but "a reading machine," merely "the models of deconstructive strategy, the terminology, the idea of literature and literary history" (38). If it is far from clear why what this machine was producing should be politically nefarious or why de Man's teaching in particular and "the message of poststructuralism in the United States" in general, should be "political conservatism" (50), the figure for this insidious intent was none other than Eliot: "Deconstruction is conservatism by default - in Paul de Man it teaches the many ways to say there is nothing to be done. The mood is all from early T.S. Eliot. We are Prufrocks all, all hollow men, who inhabit the wasteland that we now know is the humanities wing of the modern university: "Paralyzed force, gesture without motion" (51). 
No wonder deconstruction left the canon "pretty much intact" and again asserted "literary autonomy," that is, the "segregation of the literary and political functions of the intellectual" (39). For Lentricchia—and here he is clearly representative of a swarm of subsequent critical schools-literature is "all writing considered as social practice." He quotes Burke with approval: "Not only is Mein Kampf literature, it was highly effective literature" (157). For, in an italicised rebuff of Auden: "Literature makes something happen" (105). The problem, however, is that although this is invariably claimed to be achieved "through literary form" (104), in actual fact, the examples given without fail comprise contents and themes. This is the difficulty all ideological criticism encounters but for the most part refuses to acknowledge-if there is such a thing as an intellectual act, and without this premise ideological criticism itself is rather pointless - then how is an act of intellectual deliberation not acting? Or, in what sense exactly is de Man a quietist and Lentricchia a revolutionary? Have they not both wrought certain changes in the teaching of literature? (One has yet to hear of a critical book helping those in need.) If the effectiveness of literature is to be measured on the scale of millions slaughtered and world wars caused, then certainly the academy can shut up shop.

More to the point, surely no one has ever read Mein Kampf as anything else than what it is - a jingoistic call to arms and fascist propaganda-and still not everyone joined in. And what is it that makes that possible? According to Lentricchia, this can only mean that such readers have not read (or just barely) Hitler's book at all, since "if the ideology of the text and the ideology of the reader do not overlap in some substantial way, the reading experience" will "not take place, or it will barely take place" (106). Eliot, of course, could not stress his disapproval more emphatically. Most uncharacteristically, he even advances a "thesis" in this regard:

If there is "literature," if there is "poetry," then it must be possible to have full literary or poetic appreciation without sharing the beliefs of the poet. This is as far as my thesis goes in the present essay. It may be argued whether there is literature, whether there is poetry, and whether there is any meaning in the 
term "full appreciation." But I have assumed for this essay that these things exist and that these terms are understood. (1929; in 2015a: 727-28)

All hermeneutic approaches that insist that interests are constitutive of knowledge, while at the same time relying upon some variant of the non-relativist order of truth, are of course in serious trouble, as far as epistemology is concerned, even if they tend not to worry about such issues. According to Timothy Bahti, the net result of the re-orientation in critical thinking under the aegis of the so-called "new" historicism, the school of that name being but the tip of the iceberg, was historicism pure and simple only "with jazzier materials, licentious crossdressing, and lurid tales of crime and punishment, and the like" (292). In fact, historicism, which was widely reported to have returned, seems never to have left the humanities: "The preponderance of historically defined teaching and research in the modern university's study of literature leaves history today a horizon beyond which we can scarcely think. Literary studies in the university are still the heir to the historicism after Hegel” (291).

The claim that the historicist outlook underwrites most thinking about literature in the academy can be easily verified by the fact that all surveys of and readers in criticism are organised historically, moving more or less steadily towards the illumination of the present moment, while the method of presentation claims to uncover the real sources of thinking of the authors under scrutiny and the true origins of critical problems - which are all, of course, to be found in the "real world" to which the works of literature and criticism alike are supposed to refer.

In marked contrast, Eliot's stated aim is “to recognise a number of uses for poetry, without admitting that poetry must always and everywhere be subservient to any one of them" (1933; in 2015b: 685). Most importantly, however, "Poetry is of course not to be defined by its uses" (692). Examined closely, poetry and criticism prove to be especially resistant to being inserted into a framework of development or degradation. And this is no accident, according to Hans-Robert Jauss: "The form of literary history sanctioned 
by the historian is conceivably the worst medium through which to display the historicity of literature" (51). The illusions of "romantic historiography," predicated upon the "epic fictions" of the completed process, of the first beginning and the definitive end, and of the self-presenting past (cf. 53-54), exploded by Droysen, are nowhere less apposite than in art and literature. A new literary work does not present itself as absolutely new, but "predisposes its audience to a specific kind of reception by announcements, overt and covert signals, familiar characteristics, or implicit allusions" (23). The new is only ever conceivable as a historical category, for only against the background of something that is understood to be old can something else be apprehended as being new, and it is exactly this, the charting of such constellations of relations of innovation and rearrangement, that literary history should concern itself with.

It is because Eliot was of the same view that in his most famous essay, on the dialectical relation of the individual talent to tradition, he expounds his claim that the new work must be "judged by the standards of the past" by insisting on the verb he just used: "I say judged, not amputated, by them; not judged to be as good as, or worse or better than, the dead; and certainly not judged by the canons of the dead critics." What tends to happen is exactly the critical amputation that Eliot warns against, and precisely due to the lack of the historical sense, of the awareness of one's place in relation to the past and the discrimination between what is living and what is dead. "It is a judgement, a comparison, in which two things are measured by each other." The relation is again dialectical. The new work extends the whole structure (which is what the word order really means here), which for its part made it possible. There is no other way about it: "To conform merely would be for a new work not really to conform at all; it would not be new, and would therefore not be a work of art" (1919; in 2014b: 107).

The idea of conforming is here anything but conformist, as Eliot had made clear in his dissertation: "The idea, from one point of view apart from the world and from another attached to it, yet contains already the character of the world, a world, as I said before, which shows by the very fact that that 
idea can be attached to it that it is somehow prepared for the reception of that idea" (1916; in 2014a: 264). Consequently, "what happens when a new work of art is created is something that happens simultaneously to all the works of art which preceded it" (1919; in 2014b: 106). Criticism, as expounded in "Tradition and the Individual Talent" and elsewhere, is for Eliot above all a reflexive activity. To contend that "we should be none the worse for articulating what passes in our minds when we read a book and feel an emotion about it, for criticizing our own minds in their work of criticism" (105) evidently means that, since we are always already engaged in various acts of discrimination and analysis, criticism proper is an active awareness of that constitutive activity of which we of necessity must to a large degree remain unconscious, precisely in order to function as conscious beings.

That the past works become visible and progressively ever more definable in the subsequent changes of aesthetic experience, effected by the interaction between the literary work and the literary public, is precisely the function of their being past. The structures that condition the process of formation of tradition are none other than those formed by the changes of horizon, which allow for the possibilities of interpretation and comprehension. The hubris of much recent "radical criticism," predicated upon not acknowledging this, lies in the fact that it knows which of the relations are more important than others, not only which are more "relevant," but also which are "true." The most important usually overlooked assumption behind this orientation is a form of what Hilary Putnam termed the "epistemic naturalist fallacy" (297). In his analysis of historicism, he points out the "incoherence and inconsistency of positivism" which are due to the fact that "the verifiability theory of meaning is itself neither empirically testable nor mathematically provable," which forces even its proponents to concede that it is no more than a proposal. "But proposals presuppose ends and values; and it is essential doctrine for positivism that the goodness or badness of ultimate ends and values is entirely subjective." It is because of this that one critic's insight is another critic's hogwash. (The frequently encountered claim that an otherwise misguided work of criticism is really quite true as soon as it 
is read as a commentary on its author rather than on its purported subject is surely informative in this respect.) While admitting the general truth of this fact, the historically inclined critic is nevertheless able to stand aloof and observe how things really proceed. Unfortunately, the ground for the historicist's own belief is no more firm, at least philosophically: "Since there are no universally agreed upon ends or values with respect to which the positivist 'proposal' is best, it follows that the doctrine itself is merely the expression of a subjective preference for certain language forms (scientific ones) or certain goals (prediction)” (288). The prejudices of a preferred interpretive approach (historicism being a particularly instructive case in point) render the possible insights of different methods invisible by default, even as it blinds such criticism to the fact that its own manner of explanation, like any other, "is interest-relative and context-sensitive" (297). Which means that, in criticism, "there is no method except to be very intelligent," with "intelligence itself swiftly operating the analysis of sensation to the point of principle and definition" (1920; in 2014b: 267), as Eliot put it describing the perfect critic keenly aware of his own imperfection.

\section{Works Cited}

Bahti, Timothy. Allegories of History: Literary Historiography after Hegel. The Johns Hopkins UP, 1992.

Clark, Timothy. The Poetics of Singularity: The Counter-Culturalist Turn in Heidegger, Derrida, Blanchot and the Later Gadamer. Edinburgh UP, 2005.

Compagnon, Antoine. Literature, Theory, and Common sense. Translated by Carol Cosman, Princeton UP, 1998.

Eliot, T.S. After Strange Gods: A Primer of Modern Heresy. Harcourt, Brace and Co, 1934.

---. Essays Ancient and Modern. Faber and Faber, 1936.

---. The Complete Prose of T.S. Eliot, Volume 1: Apprentice Years, 1905-1918, edited by Jewel

Spears Brooker and Ronald Schuchard, The Johns Hopkins UP, 2014a.

---. The Complete Prose of T.S. Eliot, Volume 2: The Perfect Critic, 1919-1926, edited by

Anthony Cuda and Ronald Schuchard, The Johns Hopkins UP, 2014b. 
---. The Complete Prose of T.S. Eliot, Volume 3: Literature, Politics, Belief, 1927-1929, edited by Frances Dickey, Jennifer Formichelli, and Ronald Schuchard, The Johns Hopkins UP, 2015a.

---. The Complete Prose of T.S. Eliot, Volume 4: English Lion, 1930-1933, edited by Jason Harding and Ronald Schuchard, The Johns Hopkins UP, 2015b.

Faulkner, William. Novels, 1942-1954: Go Down, Moses; Intruder in the Dust; Requiem for a Nun; A Fable. Literary Classics of the United States, 1994.

Jameson, Fredric. Postmodernism; or, The Cultural Logic of Late Capitalism. Verso, 1991.

---. The Cultural Turn: Selected Writings on the Postmodern 1983-1998. Verso, 1998.

Jauss, Hans Robert. Toward an Aesthetic of Reception. Translated byTimothy Bahti, The U of Minnesota P, 1982.

Le Goff, Jacques. History and Memory. Translated by Steven Rendall and Elizabeth Claman, Columbia UP, 1992.

Lentricchia, Frank. Criticism and Social Change. The U of Chicago P, 1983.

Michaels, Walter Benn. "Forgetting Auschwitz: Jonathan Littell and the Death of a Beautiful Woman." American Literary History, vol. 25, no. 4, 2013, pp. 915-30.

Putnam, Hilary. Realism and Reason: Philosophical Papers vol. 3. Cambridge UP, 1983.

Runia, Elco. Moved by the Past: Discontinuity and Historical Mutation. Columbia UP, 2014.

Sontag, Susan. Preface to Roland Barthes, Writing Degree Zero. Translated by Annette Lavers and Colin Smith, Hill and Wang, 1968, pp. vii-xxv.

White, Hayden. The Content of the Form: Narrative Discourse and Historical Representation. The Johns Hopkins UP, 1987. 